\title{
Food Insecurity in US Families with Children with Limiting Health Conditions
}

\author{
Lea Anne DeRigne1, Linda Quinn'2, Patricia Stoddard-Dare ${ }^{3}$, Christopher Mallett ${ }^{3}$ \\ ${ }^{1}$ School of Social Work, Florida Atlantic University, Boca Raton, FL, USA \\ ${ }^{2}$ Mathemathics Department, Cleveland State University, Cleveland, $\mathrm{OH}, \mathrm{USA}$ \\ ${ }^{3}$ School of Social Work, Cleveland State University, Cleveland, OH, USA \\ Email: Iderigne@fau.edu
}

Received 9 August 2014; revised 24 September 2014; accepted 9 October 2014

Copyright (C) 2014 by authors and Scientific Research Publishing Inc.

This work is licensed under the Creative Commons Attribution International License (CC BY). http://creativecommons.org/licenses/by/4.0/

(C) $\underset{\mathrm{EY}}{\mathrm{B}}$ Open Access

\begin{abstract}
Food insecurity in US households with children with limiting health conditions was compared to households with children without limiting health conditions, controlling for demographic variables. Multivariable logistic regression was used to calculate the odds ratios. Data from the 2008-2011 Making Connections Survey $(N=1940)$ of households with children in seven high poverty communities in the US were used. Having a child with a limiting health condition made a household's odds 1.41 times $(95 \%$ C.I., $1.110,1.790)$ more likely to be food insecure. When there are two or more children with limiting conditions in the household, the odds of food insecurity are 1.67 times $(95 \% \mathrm{CI}, 1.16,2.40)$, higher than a family with no children with a disabling health condition. Families with children with limiting health conditions in high poverty communities are especially at risk of experiencing food insecurity, which can complicate health conditions. Nutrition assistance programs are vital to keep children and families food secure.
\end{abstract}

\section{Keywords}

\section{Child Health Financing, Disabilities}

\section{Introduction}

One of out every six households in the US is food insecure (defined as limited or uncertain availability of nutritionally adequate and safe foods) with nearly a quarter (24.5\%) of all children under the age of 6 living in food insecure households in 2011 [1]. Food insecurity during the childhood years is associated with health and nutrition complications, such as iron deficiency, under-nutrition, over-nutrition (obesity), increased hospitalizations, developmental delays, a lack of dietary balance, and family stress [2]-[6]. It has also been found that food inse- 
curity affects performance at school including attentiveness, eagerness to learn, interpersonal relationships and self-control [7].

Families with children with limiting health conditions (physical, learning, mental, or chronic health conditions that limit participation in the usual kinds of activities done by most children his/her age) can be especially susceptible to family financial hardship due to the increased direct (service needs) and indirect costs of disability [8]-[10]. One of the indirect costs is the impact caregiving responsibilities has on parental employment with parents reducing work hours or giving it up all together in order to provide or coordinate needed care [11]. These decisions further complicate family financial struggles. Over $20 \%$ of families with children with health conditions report financial problems due to their child's condition [12]. And, notably, reporting only on poverty rates consistently underestimates material hardship in families who have a child with a limiting health condition because hardship can be found in households with incomes above the poverty line [10]. Households raising multiple children with disabilities have been found to be even more likely to experience material hardship [13].

This article explores the question of how food insecurity differs for families with children with limiting conditions and those without in data collected during and after the severe economic downturn (2008-2011). This research analyzes data from the Annie E. Casey Foundations', Making Connections Project, which collected data from 4300 households across seven high poverty communities focusing on disadvantaged neighborhoods.

\section{Justification for the Study}

In 2013, the Food Stamp Program experienced its largest funding decrease in history with additional substantial decreases to this program coming in the following years as a result of the passed farm bill [14]. Given the close relationship between child health and nutrition, with over- and under-nutrition both contributing to medical problems, it is critical to understand the risk of food insecurity in households with vulnerable children with limiting health conditions.

Very limited prior research on this topic exists and uses National Survey of America's Families data collected between 2000 and 2002 or Survey of Income and Program Participation data collected between 2004 and 2008 [10] [13]. This study provides particular value in that it utilizes data collected between 2008-2011, which was during and after the severe economic downturn making it especially revealing of the contemporary experience of family material hardship. Additionally, this study is valuable because it analyzes the odds of food insecurity based on the number of children in the home who have a disabling health condition. Food insecurity is an exacting measure of deprivation and need and is more descriptive than simple measures of poverty. This distinction is essential since food insecurity can be present in households above the poverty line [10].

\section{Research Question}

This research evaluates whether the odds of being food insecure are different for households with children who have a limiting health condition compared to households with children who do not have a limiting health condition, after controlling for relevant demographic variables. A second analysis evaluates if having more than one child in the household with a limiting health condition changes these odds.

\section{Methods}

\subsection{Sampling Data Collection}

A cross section (Wave 3) of data from the longitudinal making connections dataset was used for this study. Data were collected between 2008 and 2011 in seven high poverty communities located in the following metropolitan areas: Des Moines, IA; Indianapolis, IN; Denver, CO; San Antonio, TX; Seattle, WA; Providence, RI; and Louisville, KY. The seven communities were chosen in order to represent the different geographic areas of the United States but were all economically disadvantaged communities. The reasons for the economic disadvantages included: declining neighborhoods in older industrial cities (Louisville, Milwaukee, Indianapolis), expanding immigrant populations (Des Moines, Hartford, Providence) and racially diverse neighborhoods with a severe shortage of affordable housing (San Antonio, Denver, Oakland, Seattle). Area probability sampling via US postal addresses was used to select a random sample of addresses ( $N=4315$ households) within the targeted neighborhoods. One adult respondent was selected to provide information about themselves, their spouse or partner (if applicable), and any children between the ages of 0 and 17 living in their residence. Response rates ranged from 
$75 \%$ to $87 \%$ among the seven sites. Households without children $(N=2375)$ were removed from analysis, leaving a total of $N=1940$ households in the analytic dataset.

Informed consent was obtained by the University of Chicago's NORC team of researchers that conducted the survey. The dataset has been stripped of identifying information so that researchers who conduct secondary data analysis are unable to make re-identification of the respondents. The authors of this paper obtained IRB approval from their perspective universities before analyzing the data. The Annie E. Casey Foundation requires that researchers go through an application and approval process before accessing the dataset including completing training on the survey and its' data. All authors of this paper underwent that process successfully.

\subsection{Data Collection and Measurement}

Respondents were administered a scripted interview which was recorded on a paper and pencil questionnaire via in-person or telephone interview. Interview surveys were available in English, Spanish, and other languages that at least $10 \%$ of the local population spoke.

The dependent variable, food insecurity, was measured by asking the adult respondent "In the last 12 months... was your family ever without enough money to buy food." Four respondents who answered "don't know" or "refused" were removed leaving a maximum of $N=1936$ households for logistic analysis. Control variables measured include adult respondent's gender ( $84.4 \%=$ female), adult respondent's age in years (median $=$ 35 years, standard deviation 11.2 years), adult respondent's self-reported race (Non-White, 70.5\%, White 29.5\%), and presence of a spouse or partner who lives in the household (yes $=11.7 \%$ ). Adult respondent's highest level of education attained was used as a proxy for household income since $27 \%$ of the values are missing for the income variable which disqualifies it as a candidate for missing data imputation. Education only has 26 missing values and was measured using a nine category ordinal variable which ranged from "eighth grade or less" to "graduate degree." The education variable's fit as a proxy was assessed by comparing observations where both variables were available, and it was found that the mean and median total household income increased as education category increased, confirming a strong positive relationship between education and total household income. One widely cited limitation of using education, as a proxy for income is that income's relationship to education varies by race and gender [15]. This potential limitation was controlled for in this study by adding both race and gender as control variables as noted above. A final control variable, food stamps status, was measured by the question, "In the past 12 months have you (or anyone in your household) received food stamps" (50.6\% = yes).

To measure the independent variable, presence of a limiting condition, respondents were asked for each child living in the household, "Has a health professional ever told you that your child has a physical, learning, mental, or chronic health condition that limits his or her participation in the usual kinds of activities done by most children his or her age or limits his or her ability to do regular school work?” This variable was coded ordinally $(0=$ no children with a disabling health condition $75.9 \%, 1=$ only one child with a disabling health condition $19.1 \%$; $2=$ two or more children with a disabling health condition $5.0 \%$ ).

To view the entire questionnaire go to: http://mcstudy.norc.org/documentation/ and to see the sample selection process go to http://mcstudy.norc.org/study-design/files/MkCon\%20Sample\%20Design.pdf.

\subsection{Data Analysis}

Chi-square analyses were run to assess the bivariate relationships between each demographic variable and whether or not the household is food insecure. Then mulitvariable logistic regression was used to calculate odds ratios with $95 \%$ confidence intervals to describe the relationship between having a child with a limiting health condition and food insecurity while controlling for relevant demographic variables. A second mulitivariable model was constructed to further define the odds of experiencing food insecurity for families that have zero, one, or more than one, child with a limiting condition.

\section{Results}

Chi square analysis revealed that food insecurity is related to all measured explanatory variables except having a spouse or partner who is present in the household (see Table 1). Table 1 displays the demographic and bivariate relationships between having a child with a limiting health condition and food insecurity breaking down the number and percentages of each of the variables. The $p$ value shows the significant relationships that exist 
Table 1. Demographic and bivariate relationships between having a child with a limiting health condition and food insecurity.

\begin{tabular}{|c|c|c|c|c|c|c|c|}
\hline \multirow{2}{*}{ Demographics } & \multicolumn{2}{|c|}{ All households } & \multicolumn{2}{|c|}{ Food insecure households } & \multicolumn{2}{|c|}{ Food secure households } & \multirow{2}{*}{$p$-value } \\
\hline & $\mathbf{n}$ & $\%$ & $\mathbf{n}$ & $\%$ & $\mathbf{n}$ & $\%$ & \\
\hline Food security (missing information on $n=4$ ) & 1936 & & 521 & $26.9 \%$ & 1415 & $73.1 \%$ & \\
\hline Respondent sex & & & & & & & 0.0014 \\
\hline Male & 303 & $15.6 \%$ & 59 & $19.5 \%$ & 244 & $80.5 \%$ & \\
\hline Female & 1635 & $84.4 \%$ & 462 & $28.3 \%$ & 1169 & $71.5 \%$ & \\
\hline Missing information & 2 & & & & & & \\
\hline Respondent race & & & & & & & 0.0486 \\
\hline Non-White & 1345 & $70.5 \%$ & 378 & $28.1 \%$ & 965 & $71.7 \%$ & \\
\hline White & 562 & $29.5 \%$ & 133 & $23.7 \%$ & 427 & $76.0 \%$ & \\
\hline Missing information & 33 & & & & & & \\
\hline Is respondent's spouse or partner present & & & & & & & 0.4105 \\
\hline No & 1680 & $88.3 \%$ & 459 & $27.3 \%$ & 1217 & $72.4 \%$ & \\
\hline Yes & 222 & $11.7 \%$ & 55 & $24.8 \%$ & 167 & $75.2 \%$ & \\
\hline Missing information & 38 & & & & & & \\
\hline Household receiving food stamps (SNAP) & & & & & & & $<0.0001$ \\
\hline No & 949 & $49.4 \%$ & 197 & $20.8 \%$ & 752 & $79.2 \%$ & \\
\hline Yes & 973 & $50.6 \%$ & 319 & $32.8 \%$ & 650 & $66.8 \%$ & \\
\hline Missing information & 18 & & & & & & \\
\hline Respondent education & & & & & & & 0.0011 \\
\hline Eighth grade or less & 207 & $10.8 \%$ & 66 & $31.9 \%$ & 140 & $67.6 \%$ & \\
\hline Beyond eighth but not high school graduate & 417 & $21.8 \%$ & 132 & $31.7 \%$ & 284 & $68.1 \%$ & \\
\hline GED—general education diploma & 150 & $7.8 \%$ & 49 & $32.7 \%$ & 101 & $67.3 \%$ & \\
\hline High school graduation & 460 & $24.0 \%$ & 117 & $25.4 \%$ & 342 & $74.3 \%$ & \\
\hline Trade or vocational school & 99 & $5.2 \%$ & 28 & $28.3 \%$ & 71 & $71.7 \%$ & \\
\hline One to three years of college & 424 & $22.2 \%$ & 99 & $23.3 \%$ & 324 & $76.4 \%$ & \\
\hline Graduated four year college & 94 & $4.9 \%$ & 15 & $16.0 \%$ & 79 & $84.0 \%$ & \\
\hline Some graduate education & 17 & $0.9 \%$ & ${ }^{*} \mathrm{ND}^{*}$ & & ${ }^{*} \mathrm{ND}^{*}$ & & \\
\hline Graduate degree & 46 & $2.4 \%$ & ${ }^{*} \mathrm{ND}^{*}$ & & ${ }^{*} \mathrm{ND}^{*}$ & & \\
\hline Missing information & 26 & & & & & & \\
\hline Any child with limiting condition & & & & & & & 0.0002 \\
\hline No & 1473 & $75.9 \%$ & 365 & $24.8 \%$ & 1105 & $75.0 \%$ & \\
\hline Yes & 467 & $24.1 \%$ & 156 & $33.4 \%$ & 310 & $66.4 \%$ & \\
\hline Number of children with limiting condition & & & & & & & 0.0007 \\
\hline 0 & 1473 & $75.9 \%$ & 365 & $24.8 \%$ & 1105 & $75.0 \%$ & \\
\hline 1 & 371 & $19.1 \%$ & 120 & $32.3 \%$ & 250 & $67.4 \%$ & \\
\hline $2+$ & 96 & $5.0 \%$ & 36 & $37.5 \%$ & 60 & $62.5 \%$ & \\
\hline
\end{tabular}




\section{Continued}

\begin{tabular}{ccccccc}
\hline & $\mathbf{n}$ & Median & $\mathbf{n}$ & Median & Median & $\boldsymbol{p}$-value \\
\hline Respondent age $(\mathbf{y r})$ & 1937 & 35 & 519 & 36 & 1414 & 0.0283 \\
Total household income (\$000) & 1413 & 22 & 395 & 17 & 1016 & 25 \\
Number of adults in household & 1940 & 2 & 521 & 2 & 1415 & 2 \\
Number of children in household & 1940 & 2 & 521 & 2 & 0.001 \\
\hline
\end{tabular}

${ }^{*} \mathrm{ND}^{*}=$ not provided due to the disclosive nature of the information as required by Annie E. Casey Foundation.

between each of the variables and food insecurity. The only variables that were not related were food insecurity and whether the respondent had a spouse or partner present in the household. This may be due to the fact that $88 \%$ of households in this sample were single parent households.

Multivariable logistic regression analysis of the variables measured found (see Table 2) adult respondent's age $(\mathrm{OR}=1.02$ per year increase, 95\% CI, 1.01 - 1.03), adult female gender ( $\mathrm{OR}=1.58,95 \% \mathrm{CI}, 1.13$ - 2.19), adult respondent's education (OR $=0.91$ per level increase in education, 95\% CI, $0.86-0.96$ ), and household receipt of food stamps (OR $=1.77,95 \% \mathrm{CI}, 1.41$ - 2.22) were all significant in explaining the odds of household food insecurity. Having a child with a limiting health condition made a household's odds 1.41 times more likely to be food insecure (95\% CI, 1.11 - 1.79) (see Table 2). These results suggest that families with children with health conditions may have higher direct and indirect costs, which put pressure on their household finances. Food security and health have a bidirectional relationship. Hunger can exacerbate health conditions and this research suggests health conditions can exacerbate food insecurity.

A second model evaluated if having more than one child in the household with a limiting health condition would change these odds. The odds ratios for all the control variables were nearly identical in both models. The odds of a household being food insecure when they have one child with a limiting condition versus no child with a limiting condition is 1.29 (95\% CI, 1.08 - 1.55). When there are two or more children with limiting conditions in the household, the odds of food insecurity are 1.67 (95\% CI, 1.16 - 2.40) times higher than a family with no children with limiting health conditions (see Table 3). Families with multiple children with limiting health conditions are even more vulnerable to food insecurity, likely because the direct and indirect costs are multiplying in these households.

\section{Discussion}

Families with children with limiting health conditions have an array of added direct and indirect costs due to their children's health conditions. Direct costs include health care expenses, copays, deductibles, fees to see specialists, medical equipment, prescription drugs and therapy services. Indirect costs can include additional child care expenses, housing renovations, and educational expenses. Indirect costs can also include loss of income that parents can experience from having to miss work in order to care for children or to take children to doctors and therapy appointments. Women especially face these challenges as their employment has been found to be more impacted than men's employment by the presence of children with limiting health conditions [11].

\subsection{Limitations}

There are some limitations to this research that must be noted. The first being that this study is not able to establish a causal relationship between children's limiting health conditions and food insecurity. Correspondingly, the direction of the relationship between children's health status and food insecurity in this cross-sectional data cannot be established. Second, although random sampling was used within the areas studied, the seven metropolitan areas themselves were selected in a non-random fashion, which limits the generalizability of these findings. Another limitation is that the data relies upon caregiver reports of both food insecurity and child's health status. Further research that may be able to clarify the extent of both variables is needed. The strength of this research is its focus on recent data during the economic recession. The importance of nutrition programs in supporting financially and health fragile families is high.

Future research should expand this inquiry to investigate the role of insurance status, receipt of coordinated care, type and severity of health condition, and receipt of government and employment benefits as they relate to 
Table 2. Multivariate relationships between having a child with a limiting health condition and household food insecurity.

\begin{tabular}{|c|c|c|c|c|}
\hline \multirow{2}{*}{$\begin{array}{c}\text { Multivariable results-model } 1 \\
\text { Respondent's age (years) }\end{array}$} & \multirow{2}{*}{$\begin{array}{c}\text { OR } \\
1.016\end{array}$} & \multicolumn{2}{|c|}{ CI } & \multirow{2}{*}{$\begin{array}{r}\boldsymbol{p} \text {-value } \\
0.0013\end{array}$} \\
\hline & & 1.006 & 1.026 & \\
\hline Respondent's sex $($ female $=1$ ) & 1.576 & 1.134 & 2.189 & 0.0067 \\
\hline Respondent's race (White $=1$ ) & 0.821 & 0.646 & 1.043 & 0.1069 \\
\hline Respondent spouse or partner $($ present $=1$ ) & 1.008 & 0.718 & 1.416 & 0.9623 \\
\hline Respondent education & 0.906 & 0.857 & 0.957 & 0.0004 \\
\hline Food stamps (yes $=1$ ) & 1.769 & 1.414 & 2.215 & 0.0001 \\
\hline Any child with a limiting conditions (yes $=1$ ) & 1.409 & 1.110 & 1.790 & 0.0049 \\
\hline
\end{tabular}

$n=1823 ;$ c statistic $=0.634$.

Table 3. Multivariable results between having multiple children with limiting health conditions and food insecurity.

\begin{tabular}{ccccc}
\hline Multivariable results-model 2 & OR & & CI & p-value \\
\hline Respondent's age (years) & 1.016 & 1.006 & 1.026 & 0.0014 \\
Respondent's sex (female $=1$ ) & 1.578 & 1.136 & 2.193 & 0.0065 \\
Respondent's race (White $=1$ ) & 0.822 & 0.647 & 1.045 & 0.1091 \\
Respondent spouse or partner (present = 1) & 1.017 & 0.724 & 1.428 & 0.923 \\
Respondent education & 0.906 & 0.858 & 0.958 & 0.0005 \\
Food stamps (yes = 1) & 1.762 & 1.407 & 2.206 & 0.0001 \\
Number of children with limiting condition $(0,1,2+)$ & 1.293 & 1.079 & 1.549 & 0.0053 \\
\hline$n=1823$; c statistic $=$ 0.635. & & & &
\end{tabular}

food insecurity and children's health status. The health benefits of systematic assessment of food insecurity, and when appropriate, referral for those most at risk is another important area for further study.

\subsection{Implications for Programs and Policies}

\subsubsection{Clinical}

Clinicians caring for children with limiting health conditions must take a holistic approach to improving the lives of their patients. Not only are children with limiting health conditions sick they may be hungry too. This research suggest that clinicians may need to screen for food insecurity with parents and older children if possible bearing in mind that discussing hunger can be culturally complex and shameful [16] [17]. A simple single question screening method has been found to be in agreement with the longer USDA created Household Food Security Survey [18]. The question is: "In the past month, was there any day when you or anyone in your family went hungry because you did not have enough money for food?” [18]. This is a quick and easy screening tool that could be integrated as a best practice in pediatric settings. If a family is found to be food insecure, then referrals to emergency food assistance programs and federal government nutrition programs need to be made. Further clinical research is needed to better understand how food insecurity affects both physical and mental health needs of patients and their families.

A second clinical model found to support families with children with limiting health conditions is to provide care in a medical home setting. Researchers have consistently found that receiving care in a medical home safeguards parental employment, which can mean less financial instability [11] [19] [20]. The most important element of the medical home model is having patient care coordination, which decreases the risk of a parent reducing work hours by 50\% [11] [19] [21]. Care coordination is a more efficient and effective means of obtaining care, consequently parents lose less work time when care is coordinated. 


\subsubsection{Policy}

There are a number of federal nutrition programs in the United States that may be able to assist food insecure households including the Supplemental Nutrition and Assistance Program (known as Food Stamps), Women, Infant, and Children (WIC), School Food Programs, and summer school feeding programs. The largest historic funding decrease to the Food Stamp program (totaling \$5 billion for fiscal year 2014) went into effect in November of 2013. On average families (of 3) lost \$29 a month (\$36 a month for a family of 4) in benefits bringing down the average benefit to $\$ 1.40$ per person per meal [22]. Over 47 million Americans rely upon the Food Stamp Program [23]. Another $\$ 8$ billion over 10 years will be cut from the Food Stamp program as a part of the 2014 Farm Bill [24]. The average cut will be $\$ 90$ a month per household [25]. Several medical associations have come out in opposition to the funding decreases in Food Stamps stating that food insecurity has a negative impact on health status [26] [27]. Reductions in this crucial food program could lead to increased health care costs as many conditions are exacerbated by food insecurity [28] [29].

Parents of children with limiting health conditions need expanded access to short-term family leave programs. The federal Family and Medical Leave Act only provides for leave on an unpaid extended time frame of up to 12 weeks. What parents of children with limiting health care conditions really need access to is short-term protected (preferably paid) sick leave that allows them to take children to doctor's appointments or to be off work for a day or two at a time when children need care. In 2006, San Francisco became the first municipality to guarantee paid sick leave to all workers [30]. In 2011, Connecticut was the first state to pass the same protection and another 20 municipalities including New York City and several states are working on advancing similar policy changes [31]. Paid sick leave would allow families to take children to doctor's appointments without a loss of income or employment.

\section{Conclusion}

In conclusion, families with children with limiting health conditions are more likely to be food insecure and families with more than one child with a health condition are even more at risk. Researchers, clinicians and policy makers must work together to support these families nutritionally and financially so that further health conditions are not exacerbated.

\section{Conflict of Interest}

None of the authors have any conflicts of interest relevant to this article.

\section{References}

[1] United States Department of Agriculture (2012) Annual Report on Food Security in the United States. Washington DC.

[2] Cook, J.T., Frank, D.A., Levenson, S.M., et al. (2006) Child Food Insecurity Increases Risks Posed by Household Food Insecurity to Young Children's Health. Journal of Nutrition, 136, 1073-1076.

[3] Cook, J.T. and Frank, D.A. (2008) Food Security, Poverty, and Human Development in the United States. In: Kaler, S.G. and Rennert, O.M., Eds., Reducing the Impact of Poverty on Health and Human Development: Scientific Approaches, Blackwell, Boston, 193-209.

[4] Casey, P.H., Szeto, M.S., Robbins, J.M., et al. (2005) Child Health-Related Quality of Life and Household Food Security. Archives of Pediatrics and Adolescent Medicine, 159, 51-56. http://dx.doi.org/10.1001/archpedi.159.1.51

[5] Hampton, T. (2007) Food Insecurity Harms Health, Well-Being of Millions in the United States. JAMA, 298, 18511853. http://dx.doi.org/10.1001/jama.298.16.1851

[6] Ryu, J. and Bartfeld, J. (2012) Household Food Insecurity during Childhood and Subsequent Health Status: The Early Childhood Longitudinal Study_Kindergarten Cohort. American Journal of Public Health, 102, 50-55. http://dx.doi.org/10.2105/AJPH.2012.300971

[7] Howard, L. (2011) Does Food Insecurity at Home Affect Non-Cognitive Performance at School? A Longitudinal Analysis of Elementary Student Classroom Behavior. Economics of Education Review, 30, 157-176. http://dx.doi.org/10.1016/j.econedurev.2010.08.003

[8] Emerson, E. and Hatton, C. (2009) Socioeconomic Positions, Poverty and Family Research. International Review of Research in Mental Retardation, 37, 97-129. http://dx.doi.org/10.1016/S0074-7750(09)37004-4

[9] Fujiura, G.T. and Yamaki, K. (2000) Trends in Demography in Childhood Poverty and Disability. Exceptional Children, 66, 187-199. 
[10] Parish, S.L., Rose, R., Grinstein-Weiss, M., Richman, E. and Andrews, M. (2008) Material Hardship in U.S. Families Raising Children with Disabilities. Exceptional Children, 75, 71-92.

[11] DeRigne, L. and Porterfield, S. (2010) Employment Change and the Role of the Medical Home for Married and SingleMother Families with Children with Special Health Care Needs. Social Science \& Medicine, 70, 631-641. http://dx.doi.org/10.1016/j.socscimed.2009.10.054

[12] Kuhlthau, K.A., Hill, K.S., Yucel, R. and Perrin, J. (2005) Financial Burden for Families of Children with Special Health Care Needs. Maternal and Child Health Journal, 9, 207-218. http://dx.doi.org/10.1007/s10995-005-4870-X

[13] Ghosh, S. and Parish, S. (2013) Prevalence and Economic Well-Being of Families Raising Multiple Children with Disabilities. Children and Youth Services Review, 35, 1431-1439. http://dx.doi.org/10.1016/j.childyouth.2013.05.018

[14] Severson, K. and Hu, W. (2013) Cut in Food Stamps Forces Hard Choices on Poor. New York Times, 8 November 2013, A1.

[15] Braveman, P.A., Cubbin, C., Egerter, S., Chideya, S., Marchi, K.S., Metzler, M. and Posner, S. (2005) Socioeconomic Status in Health Research: One Size Does Not Fit All. JAMA, 294, 2879-2888. http://dx.doi.org/10.1001/jama.294.22.2879

[16] Messer, E. and Ross, E.M. (2002) Talking to Patients about Food Insecurity. Nutrition in Clinical Care, 5, 168-181. http://dx.doi.org/10.1046/j.1523-5408.2002.00303.x

[17] Tscholl, E. and Holben, D. (2006) Knowledge and Practices of Ohio Nurse Practitioners Regarding Food Access of Patients. Journal of the American Academy of Nurse Practitioners, 18, 335-342. http://dx.doi.org/10.1111/j.1745-7599.2006.00141.x

[18] Kleinman, R.E., Murphy, J.M., Wieneke, K.M., Desmond, M.S., Schiff, A. and Gapinski, J.A. (2007) Use of a SingleQuestion Screening Tool to Detect Hunger in Families Attending a Neighborhood Health Center. Ambulatory Pediatrics, 7, 278-284. http://dx.doi.org/10.1016/j.ambp.2007.03.005

[19] Okumura, M., Cleave, J., Gnanasekaran, S. and Houtrow, A. (2009) Understanding Factors Associated with Work Loss for Families Caring for Children with a Special Health Care Need. Pediatrics, 124, S392-S398. http://dx.doi.org/10.1542/peds.2009-1255J

[20] Turchi, R., Zekarias, B., Bethell, C., Pomponio, A., Antonelli, R. and Minkovitz, C. (2009) Care Coordination for Children with Special Health Care Needs: Associations with Family-Provider Relations and Family/Child Outcomes. Pediatrics, 124, S428-S434. http://dx.doi.org/10.1542/peds.2009-1255O

[21] Looman, W., O’Connor-Von, S., Ferski, G. and Hildenbrand, D. (2009) Financial and Employment Problems in Families of Children with Special Health Care Needs: Implications for Research and Practice. Journal of Pediatric Health Care, 23, 117-125.

[22] Dean, S. and Rosenbaum, D. (2013) SNAP Benefits Will Be Cut for Nearly All Participants in November 2013. Center on Budget and Policy Priorities, Washington DC.

[23] Food Research and Action Center (2013) Food Stamp Participation. Washington DC.

[24] Nixon, R. (2014) Senate Passes Long-Stalled Farm Bill, with Clear Winners and Losers. New York Times, 4 February 2014, A15.

[25] Adach, J. (2014) Farm Bill Means Less Food for Struggling Households. Food Research and Action Center, Washington DC.

[26] Alden, E. (2013) AAP Press Statement Opposing Senate Farm Bill’s Cuts to Food Stamp Program. American Academy of Pediatrics, Washington DC.

[27] National Medical Association. African American Physicians (2014) Cuts in Food Stamps Are Detrimental to the Health of African Americans and the Underserved. Silver Spring.

[28] Ettinger de Cuba, S., Harker, L., et al. (2013) Punishing Hard Work: The Unintended Consequences of Cutting SNAP Benefits. Children's Health Watch, Washington DC.

[29] Seligman, H., Bolger, A., Guzman, D., Lopez, A. and Bibbens-Domingo, K. (2013) Exhaustion of Food Budgets at Month's End and Hospital Admissions for Hypoglycemia. Health Affairs, 33, 116-123. http://dx.doi.org/10.1377/hlthaff.2013.0096

[30] Think Progress. Newark Passes the Country’s Eighth Paid Sick Leave Law. http://thinkprogress.org/economy/2014/01/28/3214551/newark-pass-paid-sick-leave/

[31] National Partnership for Women and Families. State and Local Action on Paid Sick Days. http://go.nationalpartnership.org/site/DocServer/NP_PSD_Tracking_Doc.pdf?docID=1922 
Scientific Research Publishing (SCIRP) is one of the largest Open Access journal publishers. It is currently publishing more than 200 open access, online, peer-reviewed journals covering a wide range of academic disciplines. SCIRP serves the worldwide academic communities and contributes to the progress and application of science with its publication.

Other selected journals from SCIRP are listed as below. Submit your manuscript to us via either submit@scirp.org or Online Submission Portal.
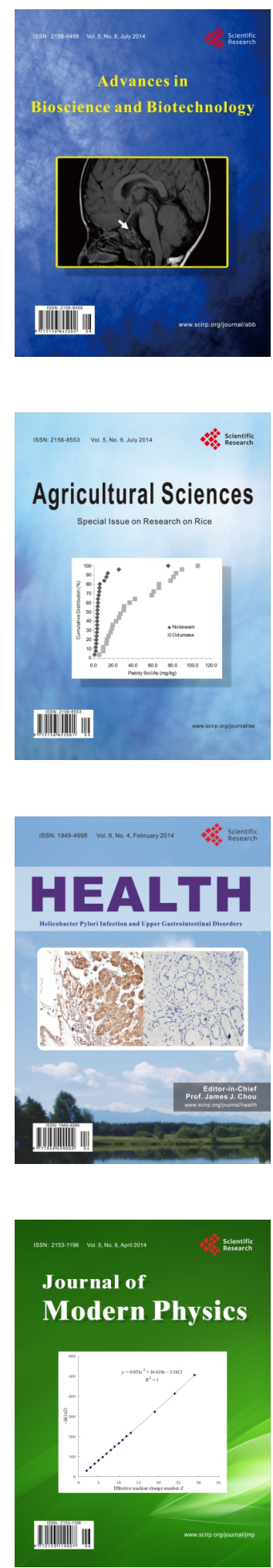
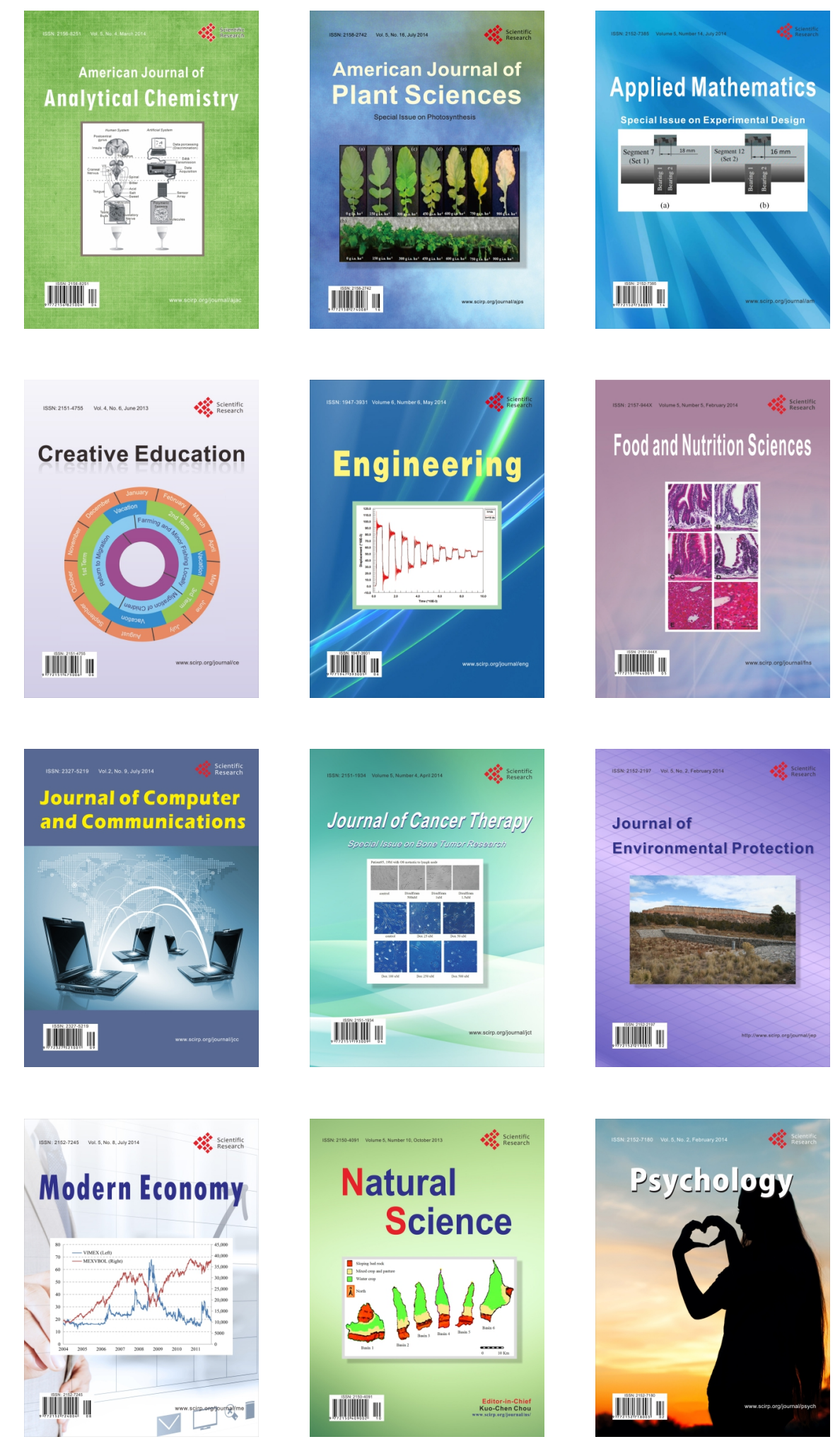